\title{
Short-Term Outcomes of Extended Pancreatectomy: A Single-Surgeon Experience
}

\author{
Tze-Yi Low ${ }^{a}$ Ye-Xin Koha ${ }^{a}$ Jin-Yao Teo ${ }^{a}$ Brian K.P. Goha, b \\ a Department of Hepatopancreatobiliary and Transplantation Surgery, Singapore General

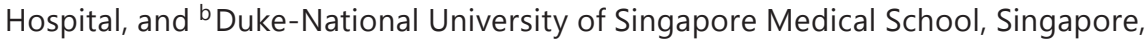 \\ Singapore
}

\section{Keywords}

Extended pancreatectomy · Outcomes · Pancreaticoduodenectomy · Vascular resection

\begin{abstract}
Background/Aims: The International Study Group of Pancreatic Surgery recently published a consensus statement on the definition of extended pancreatectomy (EP). We aimed to determine the safety profile and short-term outcomes of EP compared to standard pancreatectomy (SP). To mitigate surgeon bias, only pancreatectomies performed by a single surgeon were included. Methods: Ninety consecutive patients who underwent pancreatectomy by a single surgeon over a period of 5 years and who met our study criteria were classified into an SP or an EP group. Sixty-two patients underwent pancreaticoduodenectomy (PD), including total pancreatectomy, and 28 patients underwent distal pancreatectomy. Results: The 25 patients who underwent EP had significantly increased operation time, estimated blood loss, postoperative intensive care unit (ICU) transfer, and postoperative stay compared to the 65 patients who underwent SP. There was 1 (1.1\%) 30-day mortality and 4 (4.4\%) in-hospital mortalities. Postoperative morbidity and mortality were similar between both groups. Subgroup analysis of the patients who underwent PD demonstrated that the EP group $(n=22)$ had significantly increased operation time and postoperative ICU transfers. Conclusion: Although patients who underwent EP experienced significantly increased operative time, blood loss, and postoperative stay, they did not experience significantly higher postoperative morbidity or mortality compared to patients who underwent SP.

(C) 2017 S. Karger AG, Basel
\end{abstract}




\section{Introduction}

Cancers involving the pancreas and periampullary region have among the highest mortality rates [1]. At present, the only potentially curative treatment available for many of these tumors is complete surgical resection [2,3]. Although systemic chemotherapy with agents such as 5-FU and gemcitabine is an option, their effect is at most limited. Today, even with complete surgical resection and adjuvant chemotherapy, the median survival rates remain low at 13.4-43.1 months [4-7].

Despite this, improvements in surgical technique, equipment, neoadjuvant chemotherapy, and perioperative support have seen a greater number of patients with advanced disease being offered surgical resection. Accordingly, there has been an escalation in the number of extensive pancreatic resections performed today, adding the prospect of more morbidity to an already morbid operation [8]. Although numerous authors have previously reported their perioperative outcomes of extended pancreatectomy (EP), they utilized various definitions when using the term [9]. Recognizing these limitations and the need for a uniform definition, the International Study Group of Pancreatic Surgery (ISGPS) in 2014 published a consensus paper to standardize the definition of EP [9]. Since then, there have been only two studies reporting on the outcomes of EP according to this definition $[10,11]$. The first, a large retrospective study from Heidelberg, examined $611 \mathrm{EP}$ patients compared to 1,217 patients who underwent standard pancreatectomy (SP) over a period of about 12 years. Analysis revealed EP patients to suffer from significantly more morbidity and mortality compared to SP patients [10]. In the second study, De Reuver et al. [11] studied 111 EPs and 66 SPs, but found no difference in mortality and morbidity between them. It is important to note that both studies were based on a multisurgeon experience [10], which may have resulted in biases which can confound results.

In the present study, we aimed to determine the safety and short-term outcomes of EP as defined by the ISGPS in comparison with SP. In order to mitigate biases resulting from surgeon variability, we analyzed only surgeries performed by a single surgeon at a single institution.

\section{Methods}

Over a 64-month period from August 2011 to November 2016, 447 patients who underwent pancreatectomy at a single institution were identified from a prospectively maintained database. Of these, 92 consecutive patients who underwent pancreatectomy by a single surgeon (B.K.P. Goh) were identified. These patients were classified as having undergone SP or EP based on the ISGPS consensus definition [9]. Two patients who underwent SP but who had synchronous resections for other indications were excluded.

Clinicopathological data including patient demographics and relevant preoperative, intraoperative, and postoperative outcomes were obtained retrospectively from patient records. Clinical data were collected from a prospective computerized clinical database (Sunrise Clinical Manager version 5.8; Eclipsys Corporation, Atlanta, GA, USA), and patient clinical charts while operative data were obtained from another prospective computerized database (OTM 10; IBM, Armonk, NY, USA).

\section{Definitions}

Subtotal pancreatectomy was defined as when the transection of the pancreatic parenchyma was located at or to the right of the portal/splenic vein junction. EP was defined according to the 2014 ISGPS definition [9]. In general, any pancreaticoduodenectomy (PD), distal pancreatectomy (DP), or total pancreatectomy (TP) with adjacent organ resection such as the stomach, colon, or vascular resection due to local tumor involvement was considered an EP.

Postoperative complications were classified according to the Clavien-Dindo grading system [12] and recorded regardless of length of postoperative stay or, if the patient was discharged and readmitted, within a 30-day duration. Pancreatic fistulas were defined and graded according to the latest (2016) Inter- 
Table 1. Baseline characteristics of all patients and comparison between EP versus SP

\begin{tabular}{|c|c|c|c|c|}
\hline & $\begin{array}{l}\text { Total } \\
(n=90)\end{array}$ & $\begin{array}{l}\mathrm{EP} \\
(n=25)\end{array}$ & $\begin{array}{l}\text { SP } \\
(n=65)\end{array}$ & $p$ value \\
\hline Age, years & $62(22-82)$ & $65(44-82)$ & $62(22-80)$ & 0.304 \\
\hline Age $\geq 70$ years & $22(24.4 \%)$ & $9(36.0 \%)$ & $13(20.0 \%)$ & 0.114 \\
\hline Age $\geq 80$ years & $2(2.2 \%)$ & $1(4.0 \%)$ & $1(1.5 \%)$ & 0.478 \\
\hline Male & $36(40.0 \%)$ & $11(44.0 \%)$ & $25(38.5 \%)$ & 0.631 \\
\hline \multicolumn{5}{|l|}{ ASA score } \\
\hline 1 & $15(16.7 \%)$ & $4(16.0 \%)$ & $11(16.9 \%)$ & \multirow[t]{3}{*}{0.891} \\
\hline 2 & $58(64.4 \%)$ & $17(68.0 \%)$ & $41(63.1 \%)$ & \\
\hline 3 & $17(18.9 \%)$ & $4(16.0 \%)$ & $13(20.0 \%)$ & \\
\hline \multicolumn{5}{|l|}{ Charlson-Deyo score } \\
\hline 0 & $46(51.1 \%)$ & $12(48.0 \%)$ & $34(52.3 \%)$ & \multirow[t]{4}{*}{0.459} \\
\hline 1 & $24(26.7 \%)$ & $8(32.0 \%)$ & $16(24.6 \%)$ & \\
\hline 2 & $20(22.2 \%)$ & $5(20.0 \%)$ & $15(23.1 \%)$ & \\
\hline 3 & $5(5.6 \%)$ & $0(0.0 \%)$ & $5(7.7 \%)$ & \\
\hline \multicolumn{5}{|l|}{ Malignant tumor } \\
\hline All & $63(70.0 \%)$ & $25(100.0 \%)$ & $38(58.5 \%)$ & \multirow[t]{6}{*}{$<0.001$} \\
\hline Pancreatic adenocarcinoma & $41(45.6 \%)$ & $22(88.0 \%)$ & $19(29.2 \%)$ & \\
\hline Ampullary carcinoma & $9(10.0 \%)$ & $0(0.0 \%)$ & $9(13.8 \%)$ & \\
\hline Cholangiocarcinoma & $6(6.7 \%)$ & $1(4.0 \%)$ & $5(7.7 \%)$ & \\
\hline Duodenal carcinoma & $3(3.3 \%)$ & $1(4.0 \%)$ & $2(3.1 \%)$ & \\
\hline Others & $4(4.4 \%)$ & $1(4.0 \%)$ & $3(4.6 \%)$ & \\
\hline \multicolumn{5}{|l|}{ Type of pancreatectomy } \\
\hline Pancreaticoduodenectomy & $58(64.4 \%)$ & $19(76.0 \%)$ & $39(60.0 \%)$ & 0.156 \\
\hline Left-sided pancreatectomy & $28(31.1 \%)$ & $3(12.0 \%)$ & $25(38.5 \%)$ & 0.015 \\
\hline Total pancreatectomy & $4(4.4 \%)$ & $3(12.0 \%)$ & $1(1.5 \%)$ & 0.031 \\
\hline \multicolumn{5}{|l|}{ Approach } \\
\hline Open & $61(67.8 \%)$ & $23(92.0 \%)$ & $38(58.5 \%)$ & \multirow[t]{2}{*}{0.002} \\
\hline Laparoscopic & $29(32.2 \%)$ & $2(8.0 \%)$ & $27(41.5 \%)$ & \\
\hline
\end{tabular}

Values are presented as median (range) or $n(\%)$. Bold figures indicate statistical significance. ASA, American Society of Anesthesiologists; EP, extended pancreatectomy; SP, standard pancreatectomy.

national Study Group of Pancreatic Fistula grading [13]. Drain fluid amylase was routinely collected on postoperative day 3 and a value $>3$ times the concentration of the upper limit of serum amylase or a value $>300 \mathrm{IU} / \mathrm{L}$ associated with a clinically relevant condition was considered a clinically relevant pancreatic fistula. Grade B pancreatic fistula included patients who had surgical drains kept in place for $>3$ weeks or required endoscopic or percutaneous placement of new drains. Grade C pancreatic fistulas were fistulas which required reoperation, led to organ failure, or resulted in mortality. Purely asymptomatic fistulas previously referred to as a grade A were not classified as a pancreatic fistula or morbidity, but considered a biochemical leak.

Thirty-day mortality was defined as any death within 30 days from surgery, and in-hospital mortality was defined as any death during the index hospital stay regardless of time from surgery. Thirty-day readmissions were defined as any admission into hospital occurring within 30 days of discharge for any condition related to the primary reason for surgery and the surgery itself.

\section{Statistics}

All statistical analyses were performed using the Statistical Package for Social Sciences for Windows, version 21.0 (SPSS Inc., Chicago, IL, USA). Univariate analyses were performed using the Mann-U-Whitney test or $\chi^{2}$ tests as appropriate. All statistical tests were two-sided, and $p<0.05$ was considered statistically significant. 
Low et al:: Short-Term Outcomes of Extended Pancreatectomy: A Single-Surgeon Experience

Table 2. Perioperative outcomes of all patients and comparison between EP versus SP

\begin{tabular}{|c|c|c|c|c|}
\hline & $\begin{array}{l}\text { Total } \\
(n=90)\end{array}$ & $\begin{array}{l}\mathrm{EP} \\
(n=25)\end{array}$ & $\begin{array}{l}\text { SP } \\
(n=65)\end{array}$ & $p$ value \\
\hline Operation time, $\min$ & $385(190-775)$ & $475(215-775)$ & $340(190-698)$ & $<0.001$ \\
\hline Estimated blood loss, mL & $400(50-4,500)$ & $750(300-4,500)$ & $300(50-1,750)$ & 0.001 \\
\hline Immediate postoperative transfers to ICU & $15(16.7 \%)$ & $9(36.0 \%)$ & $6(9.2 \%)$ & 0.002 \\
\hline Postoperative stay, days & $11(3-108)$ & $16(6-108)$ & $10(3-82)$ & 0.034 \\
\hline Thirty-day readmission & $12(13.3 \%)$ & $4(16.0 \%)$ & $8(12.3 \%)$ & 0.644 \\
\hline Postoperative complication & $45(50.0 \%)$ & $15(60.0 \%)$ & $30(46.2 \%)$ & 0.153 \\
\hline Major postoperative complication (above grade II) & $32(35.6 \%)$ & $11(44.0 \%)$ & $21(32.3 \%)$ & 0.219 \\
\hline \multicolumn{5}{|l|}{ Pancreatic fistula } \\
\hline All & $13(14.4 \%)$ & $3(12.0 \%)$ & $10(15.4 \%)$ & 0.682 \\
\hline Grade B & $12(13.3 \%)$ & $3(12.0 \%)$ & $9(13.8 \%)$ & 0.817 \\
\hline Grade C & $1(1.1 \%)$ & $0(0.0 \%)$ & $1(1.5 \%)$ & 0.533 \\
\hline Biochemical leak & $33(36.7 \%)$ & $4(16.0 \%)$ & $29(44.6 \%)$ & 0.012 \\
\hline \multicolumn{5}{|l|}{ Mortality } \\
\hline Thirty-day & $1(1.1 \%)$ & $0(0.0 \%)$ & $1(1.5 \%)$ & 0.533 \\
\hline In-hospital & $4(4.4 \%)$ & $1(4.0 \%)$ & $3(4.6 \%)$ & 0.899 \\
\hline
\end{tabular}

Values are presented as median (range) or $n$ (\%). Bold figures indicate statistical significance. EP, extended pancreatectomy; ICU, intensive care unit; SP, standard pancreatectomy.

Table 3. Organs resected during extended pancreatectomy $(n=25)$

\begin{tabular}{lc}
\hline Additional organs resected (including vascular resection) & \\
1 & $22(88.0 \%)$ \\
2 & $2(8.0 \%)$ \\
3 & $0(0.0 \%)$ \\
4 & $1(4.0 \%)$ \\
Superior mesenteric vein/portal vein resection & \\
$\quad$ All & $22(88.0 \%)$ \\
$\quad$ Wedge/sleeve & $13(52.0 \%)$ \\
$\quad$ End-to-end & $5(20.0 \%)$ \\
$\quad$ Interposition graft & $4(16.0 \%)$ \\
Arterial resection & $1(4.0 \%)$ \\
Hepatectomy & $2(8.0 \%)$ \\
Gastrectomy & $1(4.0 \%)$ \\
Colectomy & $1(4.0 \%)$ \\
Choledochectomy & $1(4.0 \%)$ \\
Nephrectomy & $1(4.0 \%)$ \\
Diaphragm & $1(4.0 \%)$ \\
Others & $1(4.0 \%)$ \\
\hline
\end{tabular}

Values are presented as $n(\%)$.

\section{Results}

Ninety patients who underwent pancreatectomy between 2011 and 2016 met our study criteria. Twenty-five patients underwent EP and 65 patients SP. The baseline clinicopathological features and perioperative outcomes of the 90 patients are summarized in Tables 1 and 2, respectively. The types and number of organs resected during EP are summarized in Table 3. Most of the EPs involved vascular resection. Twenty-two (88.0\%) involved resection 
Low et al.: Short-Term Outcomes of Extended Pancreatectomy: A Single-Surgeon Experience

Table 4. Summary of the 47 major in-hospital morbidities (above grade II) which occurred in 32 patients

\begin{tabular}{|c|c|c|c|c|}
\hline & $\begin{array}{l}\text { Total } \\
(n=90)\end{array}$ & $\begin{array}{l}\mathrm{EP} \\
(n=25)\end{array}$ & $\begin{array}{l}\text { SP } \\
(n=65)\end{array}$ & $p$ value \\
\hline \multicolumn{5}{|l|}{ Grade IIIa } \\
\hline Total & $31(34.4 \%)$ & $9(36.0 \%)$ & $22(33.8 \%)$ & 0.847 \\
\hline Delayed gastric emptying requiring nasojejunal tube & $18(20.0 \%)$ & $6(24.0 \%)$ & $12(18.5 \%)$ & 0.556 \\
\hline Pancreatic fistulas & $12(12.5 \%)$ & $3(12.0 \%)$ & $9(13.8 \%)$ & 0.817 \\
\hline Requiring drainage only & $10(11.1 \%)$ & $2(8.0 \%)$ & $8(15.4 \%)$ & \\
\hline With bleeding requiring embolization only & $1(1.1 \%)$ & $1(4.0 \%)$ & $0(0.0 \%)$ & \\
\hline Requiring both drainage and embolization & $1(1.1 \%)$ & $0(0.0 \%)$ & $1(1.5 \%)$ & \\
\hline \multicolumn{5}{|l|}{ Non-PF-related bleeding } \\
\hline Gastrojejunal staple line bleed & $1(1.1 \%)$ & $0(0.0 \%)$ & $1(1.5 \%)$ & 0.533 \\
\hline \multicolumn{5}{|l|}{ Grade IIIb } \\
\hline Total & $9(10.0 \%)$ & $4(16.0 \%)$ & $5(7.7 \%)$ & 0.497 \\
\hline Pancreatic fistula requiring reoperation & $1(1.1 \%)$ & $0(0.0 \%)$ & $1(1.5 \%)$ & 0.533 \\
\hline Postoperative bleeding & $6(6.7 \%)$ & $2(8.0 \%)$ & $4(6.2 \%)$ & 0.702 \\
\hline From pancreatic stump & $3(3.3 \%)$ & $0(0.0 \%)$ & $3(4.6 \%)$ & \\
\hline From other vessels & $3(3.3 \%)$ & $2(8.0 \%)$ & $1(1.5 \%)$ & \\
\hline Portal vein/superior mesenteric vein thrombosis & $2(2.2 \%)$ & $2(8.0 \%)$ & $0(0.0 \%)$ & \\
\hline \multicolumn{5}{|l|}{ Grade IV } \\
\hline All & $3(3.3 \%)$ & $2(8.0 \%)$ & $1(1.5 \%)$ & 0.126 \\
\hline Respiratory failure requiring ventilatory support & $2(2.2 \%)$ & $1(4.0 \%)$ & $1(1.5 \%)$ & \\
\hline Septic shock & $1(1.1 \%)$ & $1(4.0 \%)$ & $0(0.0 \%)$ & \\
\hline \multicolumn{5}{|l|}{ Grade V } \\
\hline Total & $4(4.4 \%)$ & $1(4.0 \%)$ & $3(4.6 \%)$ & 0.689 \\
\hline Pneumonia & $3(3.3 \%)$ & $1(4.0 \%)$ & $2(3.1 \%)$ & \\
\hline Respiratory arrest from anoxic brain injury & $1(1.1 \%)$ & $0(0.0 \%)$ & $1(1.5 \%)$ & \\
\hline
\end{tabular}

Values are presented as n (\%). Patients may have experienced more than one morbidity. EP, extended pancreatectomy; PF, pancreatic fistula; SP, standard pancreatectomy.

of either the superior mesenteric vein (SMV) or the portal vein. One (4.0\%) patient underwent arterial resection and reconstruction, which was done concomitantly with resection of the SMV.

\section{Morbidities}

Postoperative morbidity occurred in $45(50.0 \%)$ patients and was not significantly different between both groups. Thirty-two (35.6\%) of these were major (above grade II) morbidities, including 18 grade IIIa, 7 grade IIIb, 3 grade IV, and 4 grade V morbidities. Overall, there were 47 different major morbidities occurring in these 32 patients, which are summarized in Table 4.

There were 31 grade IIIa complications which occurred in 27 patients. Of these, the most common was delayed gastric emptying requiring endoscopic insertion of a nasojejunal tube $(n=18)$, followed by grade B pancreatic fistulas $(n=12)$. Nine $(10.0 \%)$ patients experienced grade IIIb complications and required repeat surgery. Six (6.7\%) patients underwent re-laparotomy for postoperative bleeding, of which 3 (3.3\%) were for pancreatogastrostomy stump bleed, $1(1.1 \%)$ was for middle colic artery bleed, another one $(1.1 \%)$ was for a jejunal vessel bleed, and the last one (1.1\%) was for a bleeding gastrojejunal anastomotic ulcer. Of the remaining 3 patients, 1 patient who had undergone standard PD required a laparotomy with washout and subsequent completion pancreatosplenectomy for pancreatic ascites. Two 
others who had EP with venous resection required open thrombectomy for venous thrombosis. One of the 2 patients who underwent EP with SMV resection had repeated thrombosis of the vessel resulting in gastrojejunostomy anastomotic dehiscence and required a second revision of the SMV anastomosis with a polytetrafluoroethylene (PTFE) graft in addition to a refashioning of the gastrojejunostomy anastomosis. Two of the 9 patients $(22.2 \%)$ who required reoperations eventually demised. One was from nosocomial pneumonia and the other from anoxic brain injury after respiratory arrest.

Overall, 13 patients $(14.4 \%)$ had pancreatic fistulas, of which $12(91.7 \%)$ were grade B and $1(8.3 \%)$ was a grade $C$ fistula requiring reoperation. One of the grade B fistulas which initially required percutaneous drainage also subsequently required angioembolization for bleeding. Thirty-three patients had a biochemical leak.

\section{Mortality}

No difference in mortality was demonstrated between the EP and the SP group. There was one 30-day mortality and 4 (4.4\%) in-hospital mortalities (Table 4). Three were due to nosocomial pneumonia and 1 was due to anoxic brain injury from respiratory arrest. The 4 in-hospital mortalities are briefly described as follows. The first mortality was a patient who underwent an extended Whipple procedure with SMV resection and PTFE graft reconstruction for locally advanced pancreatic cancer. Postoperatively she developed upper gastrointestinal bleeding on postoperative day (POD) 15 from a 1-cm gastrojejunostomy ulcer which required reoperation, gastrostomy, and oversewing of the ulcer. She subsequently developed nosocomial pneumonia which resulted in her demise. The second occurred in a post-renal transplant patient who underwent a Whipple procedure for a $7-\mathrm{cm}$ intraductal papillary mucinous neoplasm. She developed a grade B pancreatic fistula which was treated via percutaneous drainage. Although the collections resolved, she developed overwhelming sepsis from nosocomial pneumonia and eventually succumbed. The third mortality occurred in a patient who underwent a Whipple procedure for pancreatic head adenocarcinoma. Postoperatively, he developed a pancreatic fistula requiring endoscopic transgastric drainage on POD 13. He remained stable until POD 49 when he developed pancreatic ascites due to migration of the transgastric stent. He underwent laparotomy and washout, and although the reoperation was uneventful, he developed sudden respiratory arrest and required cardiopulmonary resuscitation in the operating room recovery area immediately after extubation. This was attributed to an idiosyncratic reaction to polymyxin $B$ after general anesthesia, and the patient sustained severe hypoxic brain injury. He remained in a coma and subsequently demised from respiratory failure after 2 months. The final mortality was in an American Society of Anesthesiologists (ASA) score 3 patient who had a recent myocardial infarction 2 months before surgery. He underwent laparoscopic DP for a pancreatic tail adenocarcinoma and postoperatively developed a grade B pancreatic fistula requiring percutaneous drainage. Unfortunately, his stay was complicated by nontraumatic intracranial hemorrhage on POD 10 followed by an acute myocardial infarction on POD 21. He developed further complications of pneumonia and eventually demised on POD 69.

\section{Comparison between the Baseline Characteristics and Outcomes of EP versus SP}

There was no difference between the baseline characteristics such as age, sex, ASA score, or Charlson-Deyo score of the two groups on univariate analysis (Table 1). Patients who underwent EP were significantly more likely to have malignant tumors, to undergo open surgery, and to require TP compared to patients who underwent SP. They were also significantly less likely to undergo DP compared to patients who underwent SP. All 25 patients who underwent EP had a malignant tumor, compared to only 38 (58.5\%) of those 
Low et al.: Short-Term Outcomes of Extended Pancreatectomy: A Single-Surgeon Experience

Table 5. Baseline characteristics and outcomes in the pancreaticoduodenectomy including total pancreatectomy subgroup

\begin{tabular}{|c|c|c|c|c|}
\hline & $\begin{array}{l}\text { Total } \\
(n=62)\end{array}$ & $\begin{array}{l}\text { EP } \\
(n=22)\end{array}$ & $\begin{array}{l}\text { SP } \\
(n=40)\end{array}$ & $p$ value \\
\hline Age, years & $63(44-82)$ & $65(44-82)$ & $62(44-79)$ & 0.480 \\
\hline Age $\geq 70$ years & $17(27.4 \%)$ & $8(36.3 \%)$ & $9(22.5 \%)$ & 0.242 \\
\hline Age $\geq 80$ years & $1(1.6 \%)$ & $1(4.5 \%)$ & $0(0.0 \%)$ & 0.174 \\
\hline Male & $28(45.2 \%)$ & $10(45.5 \%)$ & $18(45.0 \%)$ & 0.973 \\
\hline \multicolumn{5}{|l|}{ ASA score } \\
\hline 1 & $9(14.5 \%)$ & $3(13.6 \%)$ & $6(15.0 \%)$ & \multirow[t]{3}{*}{0.536} \\
\hline 2 & $40(64.5 \%)$ & $16(72.7 \%)$ & $24(60.0 \%)$ & \\
\hline 3 & $13(21.0 \%)$ & $3(13.6 \%)$ & $10(25.0 \%)$ & \\
\hline \multicolumn{5}{|l|}{ Charlson-Deyo score } \\
\hline 0 & $27(43.5 \%)$ & $10(45.5 \%)$ & $17(42.5 \%)$ & \multirow[t]{4}{*}{0.455} \\
\hline 1 & $19(30.6 \%)$ & $8(36.3 \%)$ & $11(27.5 \%)$ & \\
\hline 2 & $12(19.4 \%)$ & $4(18.1 \%)$ & $8(20.0 \%)$ & \\
\hline 3 & $4(0.06 \%)$ & $0(0.0 \%)$ & $4(10.0 \%)$ & \\
\hline \multicolumn{5}{|l|}{ Malignant tumor } \\
\hline All & $55(88.7 \%)$ & $22(100.0 \%)$ & $33(82.5 \%)$ & \multirow[t]{6}{*}{0.011} \\
\hline Pancreatic adenocarcinoma & $35(56.5 \%)$ & $20(90.9 \%)$ & $15(37.5 \%)$ & \\
\hline Ampullary carcinoma & $9(14.5 \%)$ & $0(0.0 \%)$ & $9(22.5 \%)$ & \\
\hline Cholangiocarcinoma & $6(9.7 \%)$ & $1(4.5 \%)$ & $5(12.5 \%)$ & \\
\hline Duodenal carcinoma & $3(4.8 \%)$ & $1(4.5 \%)$ & $2(5.0 \%)$ & \\
\hline Others & $2(3.2 \%)$ & $0(0.0 \%)$ & $2(5.0 \%)$ & \\
\hline \multicolumn{5}{|l|}{ Pancreatic anastomosis reconstruction } \\
\hline Pancreaticogastrostomy & $37(59.7 \%)$ & $9(40.1 \%)$ & $28(70.0 \%)$ & \multirow[t]{3}{*}{0.065} \\
\hline Pancreaticojejunostomy & $21(33.9 \%)$ & $10(45.5 \%)$ & $11(27.5 \%)$ & \\
\hline Total pancreatectomy & $4(6.5 \%)$ & $3(13.6 \%)$ & $1(2.5 \%)$ & \\
\hline \multicolumn{5}{|l|}{ Approach } \\
\hline Open & $57(91.9 \%)$ & $21(95.5 \%)$ & $36(90.0 \%)$ & \multirow[t]{2}{*}{0.450} \\
\hline Laparoscopic & $5(8.1 \%)$ & $1(4.5 \%)$ & $4(10.0 \%)$ & \\
\hline Operation time, $\min$ & $392.5(215-770)$ & $480(215-770)$ & $344.5(240-698)$ & $<0.001$ \\
\hline Estimated blood loss, $\mathrm{mL}$ & $500(100-4,500)$ & $700(300-4,500)$ & $300(100-1,750)$ & 0.008 \\
\hline Immediate postoperative transfers to ICU & $17(27.4 \%)$ & $10(45.5 \%)$ & $7(17.5 \%)$ & 0.018 \\
\hline Postoperative stay, days & $15(7-108)$ & $16(8-108)$ & $13.5(7-82)$ & 0.871 \\
\hline Thirty-day readmission & $13(21.0 \%)$ & $4(18.2 \%)$ & $9(22.5 \%)$ & 0.689 \\
\hline Postoperative complication & $37(59.7 \%)$ & $13(59.1 \%)$ & $24(60.0 \%)$ & 0.944 \\
\hline Major postoperative complication (above grade II) & $27(43.5 \%)$ & $9(40.9 \%)$ & $18(45.0 \%)$ & 0.756 \\
\hline \multicolumn{5}{|l|}{ Pancreatic fistula } \\
\hline All & $8(12.9 \%)$ & $2(9.1 \%)$ & $6(15.0 \%)$ & 0.507 \\
\hline Grade B & $7(11.3 \%)$ & $2(9.1 \%)$ & $5(12.5 \%)$ & 0.685 \\
\hline Grade C & $1(1.6 \%)$ & $0(0.0 \%)$ & $1(2.5 \%)$ & 0.455 \\
\hline Biochemical leak & $17(27.4 \%)$ & $4(18.1 \%)$ & $13(32.5 \%)$ & 0.227 \\
\hline \multicolumn{5}{|l|}{ Mortality } \\
\hline Thirty-day & $1(1.6 \%)$ & $0(0.0 \%)$ & $1(2.5 \%)$ & 0.455 \\
\hline In-hospital & $3(4.8 \%)$ & $1(4.5 \%)$ & $2(5.0 \%)$ & 0.936 \\
\hline
\end{tabular}

Values are presented as median (range) or $n$ (\%). Bold figures indicate statistical significance. ASA, American Society of Anesthesiologists; EP, extended pancreatectomy; ICU, intensive care unit; SP, standard pancreatectomy.

who underwent SP. Pancreatic cancers made up the bulk of malignant tumors $(n=41)$. Of the 25 EPs, only $2(8.0 \%)$ were performed laparoscopically, compared to $27(41.5 \%)$ surgeries in the SP group.

On univariate analysis, operative time, estimated blood loss, postoperative intensive care unit (ICU) transfer, and postoperative duration of stay were significantly higher in patients who underwent EP compared to those who underwent SP (Table 2). There was no difference in 30-day readmission rates and postoperative complication rates. 
Low et al.: Short-Term Outcomes of Extended Pancreatectomy: A Single-Surgeon Experience

Comparison between the Baseline Characteristics and Outcomes of EP versus SP in the 62 Patients Who Underwent PD/TP

Subgroup analysis of patients who underwent only PD including TP revealed no difference between their baseline characteristics, other than patients who underwent EP and were more likely to have malignant tumors (Table 5). Patients who underwent EP were significantly more likely to have a longer operation time and to be transferred to the ICU postoperatively, although there was no significant difference in blood loss, postoperative morbidity, or length of stay.

\section{Discussion}

Reinforced by advancements in techniques, equipment, and perioperative care, EP has become increasingly commonplace in the management of locally advanced cancers over the past decade, especially in large tertiary care centers [9]. Underpinning this trend is the fact that pancreatic cancer tends to present late and that complete surgical resection still offers the best chance of disease-specific survival $[3,14,15]$. Indeed, various papers have reported improved 5-year survival rates of between $12 \%$ and as high as $27 \%$ after resection in recent years [16-19].

In the present study, the vast majority of resections in the EP group were PDs. Although it is difficult to explain the exact reason behind the relatively small numbers of DPs and TPs which were extended resections, possible reasons behind this observation include (1) that pancreatic malignancies in the body and tail frequently present at a late and inoperable stage and most would have presented with metastases, and (2) that locally advanced pancreatic malignancies in the body frequently invade the celiac axis, requiring a DP with celiac axis resection. However, at present we do not routinely perform arterial resection and reconstruction for pancreatic malignancy at our institution, as we believe that aggressive resection for cancers involving the artery may be of little benefit to patient survival.

Unsurprisingly, EP has its attendant costs. Analysis of our EP revealed significantincreases in operative time, estimated blood loss, postoperative ICU transfers, and postoperative stay compared to SP. These findings are also largely concordant with the results of other large studies reported by other authors [11, 20-22]. In our present study, no difference in postoperative morbidity or mortality rates between EP and SP was demonstrated. This was in agreement with the study by Nikfarjam et al. [22], who also reported similar morbidity and mortality in their study of 105 patients who underwent PD. Likewise, De Reuver et al. [11] found no difference in either perioperative morbidity (38\% in SP vs. 35\% in EP) or mortality ( $0 \%$ for both) in his study of 177 patients who underwent PD for ductal adenocarcinoma. Similar findings were also reported for patients who underwent DP with multivisceral resection by Seeliger et al. [23] and Sahakyan et al. [24], both of whom reported comparable morbidity but not mortality rates, and Panzeri et al. [25], who reported comparable morbidity and mortality rates.

This highlights an important point, namely that although one would logically expect EP to be associated with a higher morbidity compared to SP due to the magnitude of the surgery, on the contrary, these resections frequently are associated with a decreased rate of pancreatic fistula, which is the most common and dreaded morbidity after pancreatectomies. This is because patients who undergo EP frequently have locally advanced pancreatic malignancies which are associated with a firm pancreas and dilated pancreatic duct, compared to SP for early periampullary cancers or premalignant tumors which are associated with a soft pancreas and small duct. Nonetheless, in this study SP was only significantly associated with a higher rate of biochemical leak but not clinically significant pancreatic fistula, possibly due to the small sample size resulting in a type 2 error. 
Larger studies which included the various types of pancreatectomies have found contrasting results. Bhayani et al. [21] analyzed 273 extended PDs from the National Surgical Quality Improvement Project database over 6 years and found significantly increased morbidity and a three-fold increase in mortality compared to patients who underwent SP. Hartwig et al. [20] found increased morbidity but comparable mortality in their 2009 matchedpair analysis of 101 patients who underwent multivisceral pancreatic resection. In their study however, patients with additional portal vein resection or splenectomy that was not done in the context of DP or TP were not considered as having undergone multivisceral resection, although they were included in the analysis of morbidity and mortality. In their more recent study of over 1,800 patients who underwent pancreatectomy for borderline resectable tumors, Hartwig et al. [10] found significantly increased rates of delayed gastric emptying, re-laparotomy, and mortality in patients who underwent EP. With respect to DP, multivisceral resection has also been found to increase the odds of overall morbidity [26, 27].

\section{Long-Term Outcomes}

Studies examining the long-term survival outcomes in EP are limited with conflicting results. Various studies have showed improved survival [28], with some quoting comparable 5-year rates of 16-35.5\% [29-31]. In contrast, other studies have demonstrated a significant difference in favor of the standard resection group. In the study by Hartwig et al. [10], both median and 5-year survival rates were reduced in the EP group, even after correcting for perioperative mortality. Sahakyan et al. [24] reported a decreased median survival times of 20.2 months in the EP group versus 33.3 months in the SP group in their series of 196 laparoscopic DPs. Similarly, De Reuver et al. [11] also reported decreased survival times of 18.5 months in the EP group versus 32.1 months in the SP group in their PD series. These studies have also identified a multitude of factors such as increased age [10], higher tumor grade [10,11, 29], larger tumor size [28, 32], positive lymph nodes [10, 11, 29], incomplete resection [10, 11], perineural invasion [11], prolonged operating time [10], intraoperative transfusion [28], and increased blood loss [10] as negative predictive factors for long-term survival.

\section{Vascular Resection}

Comparatively, pancreatectomy with vascular resection, a subset of EP, has been demonstrated by large studies [33-35], including systematic reviews [36-38] and a meta-analysis [39], to be largely of comparable morbidity, mortality, and long-term outcomes to SP. The only point of contention lies with arterial resections, with one study showing a poorer survival rate despite reducing the risk of local tumor recurrence [40], and a meta-analysis showing increased perioperative and long-term mortality [41]. Only Christians et al. [42] managed to achieve similar morbidity and mortality rates in their carefully selected group of patients who underwent neoadjuvant chemotherapy. Considering that the vast majority (84.0\%) of our EP patients underwent only venous resection, our results are consistent with those of the above studies. Furthermore, this suggests that the poorer outcome of EP patients seems to stem from the concomitant organ resection, an observation supported by Hartwig et al.'s 2009 paper on multivisceral resection [20]. Despite this, in their more recent study, multiorgan resection and arterial resection were not shown to increase mortality on multivariate analysis, although they were significant on univariate analysis [10]. Thus, further analysis and research is still required to establish this postulation.

\section{Limitations}

There are several potential limitations associated with this study. Firstly, due to the relatively small sample size, the statistical analysis could have been affected by a type 2 error. Secondly, the data only represent the experience of a single surgeon in a tertiary-level center, 
which may limit its generalization to other institutions. However, in our opinion the inclusion of only cases performed by a single surgeon over a relatively short time span is a major strength of our study, as it mitigates biases arising from previous studies which included EP performed by multiple surgeons over a relatively long time period.

\section{Conclusion}

In this single-surgeon study, we found that although patients who underwent EP experienced significantly increased operative time, blood loss, and postoperative stay, they did not experience significantly higher postoperative morbidity or mortality compared to patients who underwent SP.

\section{Statement of Ethics}

The study was approved by the SingHealth Institutional Review Board.

\section{Disclosure Statement}

The authors declare no conflicts of interest.

\section{References}

1 Siegel RL, Miller KD, Jemal A: Cancer statistics, 2016. CA Cancer J Clin 2016;66:7-30.

2 Raut CP, Tseng JF, Sun CC, Wang H, Wolff RA, Crane CH, Hwang R, Vauthey JN, Abdalla EK, Lee JE, Pisters PW, Evans DB: Impact of resection status on pattern of failure and survival after pancreaticoduodenectomy for pancreatic adenocarcinoma. Ann Surg 2007;246:52-60.

3 Wagner M, Redaelli C, Lietz M, Seiler CA, Friess H, Büchler MW: Curative resection is the single most important factor determining outcome in patients with pancreatic adenocarcinoma. Br J Surg 2004;91:586-594.

4 Neoptolemos JP, Moore MJ, Cox T, Valle JW, Palmer DH, McDonald AC, Carter R, Tebbutt NC, Dervenis C, Smith D, Glimelius B, Charnley RM, Lacaine F, Scarfe AG, Middleton MR, Anthoney A, Ghaneh P, Halloran CM, Lerch MM, Oláh A, Rawcliffe CL, Verbeke CS, Campbell F, Büchler MW; European Study Group for Pancreatic Cancer: Effect of adjuvant chemotherapy with fluorouracil plus folinic acid or gemcitabine vs observation on survival in patients with resected periampullary adenocarcinoma: the ESPAC-3 Periampullary Cancer Randomized Trial. JAMA 2012;308:147-156.

5 Herman JM, Swartz MJ, Hsu CC, Winter J, Pawlik TM, Sugar E, Robinson R, Laheru DA, Jaffee E, Hruban RH, Campbell KA, Wolfgang CL, Asrari F, Donehower R, Hidalgo M, Diaz LA Jr, Yeo C, Cameron JL, Schulick RD, Abrams R: Analysis of fluorouracil-based adjuvant chemotherapy and radiation after pancreaticoduodenectomy for ductal adenocarcinoma of the pancreas: results of a large, prospectively collected database at the Johns Hopkins Hospital. J Clin Oncol 2008;26:3503-3510.

6 Oettle H, Post S, Neuhaus P, Gellert K, Langrehr J, Ridwelski K, Schramm H, Fahlke J, Zuelke C, Burkart C, Gutberlet K, Kettner E, Schmalenberg H, Weigang-Koehler K, Bechstein WO, Niedergethmann M, Schmidt-Wolf I, Roll L, Doerken B, Riess H: Adjuvant chemotherapy with gemcitabine vs observation in patients undergoing curative-intent resection of pancreatic cancer: a randomized controlled trial. JAMA 2007;297:267-277.

7 Hsu CC, Herman JM, Corsini MM, Winter JM, Callister MD, Haddock MG, Cameron JL, Pawlik TM, Schulick RD, Wolfgang CL, Laheru DA, Farnell MB, Swartz MJ, Gunderson LL, Miller RC: Adjuvant chemoradiation for pancreatic adenocarcinoma: the Johns Hopkins Hospital-Mayo Clinic collaborative study. Ann Surg Oncol 2010;17:981-990.

8 Shrikhande SV, Barreto SG: Extended pancreatic resections and lymphadenectomy: an appraisal of the current evidence. World J Gastrointest Surg 2010;2:39-46.

9 Hartwig W, Vollmer CM, Fingerhut A, Yeo CJ, Neoptolemos JP, Adham M, Andrén-Sandberg A, Asbun HJ, Bassi C, Bockhorn M, Charnley R, Conlon KC, Dervenis C, Fernandez-Cruz L, Friess H, Gouma DJ, Imrie CW, Lillemoe KD, Milićević MN, Montorsi M, Shrikhande SV, Vashist YK, Izbicki JR, Büchler MW; International Study Group on Pancreatic Surgery: Extended pancreatectomy in pancreatic ductal adenocarcinoma: definition and consensus of the International Study Group for Pancreatic Surgery (ISGPS). Surgery 2014;156:1-14. 
10 Hartwig W, Gluth A, Hinz U, Koliogiannis D, Strobel O, Hackert T, Werner J, Büchler MW: Outcomes after extended pancreatectomy in patients with borderline resectable and locally advanced pancreatic cancer. Br J Surg 2016;103:1683-1694.

11 De Reuver PR, Mittal A, Neale M, Gill AJ, Samra JS: Extended pancreatoduodenectomy as defined by the International Study Group for Pancreatic Surgery is associated with worse survival but not with increased morbidity. Surgery 2015;158:183-190.

12 Dindo D, Demartines N, Clavien PA: Classification of surgical complications: a new proposal with evaluation in a cohort of 6336 patients and results of a survey. Ann Surg 2004;240:205-213.

13 Bassi C, Marchegiani G, Dervenis C, Sarr M, Abu Hilal M, Adham M, Allen P, Andersson R, Asbun HJ, Besselink MG, Conlon K, Del Chiaro M, Falconi M, Fernandez-Cruz L, Fernandez-Del Castillo C, Fingerhut A, Friess H, Gouma DJ, Hackert T, Izbicki J, Lillemoe KD, Neoptolemos JP, Olah A, Schulick R, Shrikhande SV, Takada T, Takaori K, Traverso W, Vollmer CR, Wolfgang CL, Yeo CJ, Salvia R, Buchler M; International Study Group on Pancreatic Surgery (ISGPS): The 2016 update of the International Study Group (ISGPS) definition and grading of postoperative pancreatic fistula: 11 years after. Surgery 2017;161:584-591.

14 Hackert T, Ulrich A, Büchler MW: Borderline resectable pancreatic cancer. Cancer Lett 2016;375:231-237.

15 Gaedcke J, Gunawan B, Grade M, Szöke R, Liersch T, Becker H, Ghadimi BM: The mesopancreas is the primary site for R1 resection in pancreatic head cancer: relevance for clinical trials. Langenbecks Arch Surg 2010;395: 451-458.

16 Ferrone CR, Pieretti-Vanmarcke R, Bloom JP, Zheng H, Szymonifka J, Wargo JA, Thayer SP, Lauwers GY, Deshpande V, Mino-Kenudson M, Fernández-del Castillo C, Lillemoe KD, Warshaw AL: Pancreatic ductal adenocarcinoma: long-term survival does not equal cure. Surgery 2012;152(3 suppl 1):S43-S49.

17 Adham M, Jaeck D, Le Borgne J, Oussoultzouglou E, Chenard-Neu MP, Mosnier JF, Scoazec JY, Mornex F, Partensky C: Long-term survival (5-20 years) after pancreatectomy for pancreatic ductal adenocarcinoma: a series of 30 patients collected from 3 institutions. Pancreas 2008;37:352-357.

18 Katz MH, Wang H, Fleming JB, Sun CC, Hwang RF, Wolff RA, Varadhachary G, Abbruzzese JL, Crane CH, Krishnan S, Vauthey JN, Abdalla EK, Lee JE, Pisters PW, Evans DB: Long-term survival after multidisciplinary management of resected pancreatic adenocarcinoma. Ann Surg Oncol 2009;16:836-847.

19 Ferrone CR, Brennan MF, Gonen M, Coit DG, Fong Y, Chung S, Tang L, Klimstra D, Allen PJ: Pancreatic adenocarcinoma: the actual 5-year survivors. J Gastrointest Surg 2008;12:701-706.

20 Hartwig W, Hackert T, Hinz U, Hassenpflug M, Strobel O, Büchler MW, Werner J: Multivisceral resection for pancreatic malignancies: risk-analysis and long-term outcome. Ann Surg 2009;250:81-87.

21 Bhayani NH, Enomoto LM, James BC, Ortenzi G, Kaifi JT, Kimchi ET, Staveley-O'Carroll KF, Gusani NJ: Multivisceral and extended resections during pancreatoduodenectomy increase morbidity and mortality. Surgery 2014;155:567-574.

22 Nikfarjam M, Sehmbey M, Kimchi ET, Gusani NJ, Shereef S, Avella DM, Staveley-O'Carroll KF: Additional organ resection combined with pancreaticoduodenectomy does not increase postoperative morbidity and mortality. J Gastrointest Surg 2009;13:915-921.

23 Seeliger H, Christians S, Angele MK, Kleespies A, Eichhorn ME, Ischenko I, Boeck S, Heinemann V, Jauch KW, Bruns CJ: Risk factors for surgical complications in distal pancreatectomy. Am J Surg 2010;200:311-317.

24 Sahakyan MA, Kazaryan AM, Rawashdeh M, Fuks D, Shmavonyan M, Haugvik SP, Labori KJ, Buanes T, Røsok B, Ignjatovic D, Abu Hilal M, Gayet B, Kim SC, Edwin B: Laparoscopic distal pancreatectomy for pancreatic ductal adenocarcinoma: results of a multicenter cohort study on 196 patients. Surg Endosc 2016;30:34093418.

25 Panzeri F, Marchegiani G, Malleo G, Malpaga A, Maggino L, Marchese T, Salvia R, Bassi C, Butturini G: Distal pancreatectomy associated with multivisceral resection: results from a single centre experience. Langenbecks Arch Surg 2017;402:457-464.

26 Kleeff J, Diener MK, Z'graggen K, Hinz U, Wagner M, Bachmann J, Zehetner J, Müller MW, Friess H, Büchler MW: Distal pancreatectomy: risk factors for surgical failure in 302 consecutive cases. Ann Surg 2007;245:573-582.

27 Goh BK, Tan YM, Chung YF, Cheow PC, Ong HS, Chan WH, Chow PK, Soo KC, Wong WK, Ooi LL: Critical appraisal of 232 consecutive distal pancreatectomies with emphasis on risk factors, outcome, and management of the postoperative pancreatic fistula. Arch Surg 2008;143:956-965.

28 Guo ZH, Tan CL, Chen HY, Ke NW, Li A, Liu XB: Viability of extended distal pancreatectomy for pancreatic adenocarcinoma of the body or tail. Zhonghua Wai Ke Za Zhi 2016;54:201-205.

29 Shoup M, Conlon KC, Klimstra D, Brennan MF: Is extended resection for adenocarcinoma of the body or tail of the pancreas justified? J Gastrointest Surg 2003;7:946-952.

30 Sasson AR, Hoffman JP, Ross EA, Kagan SA, Pingpank JF, Eisenberg BL: En bloc resection for locally advanced cancer of the pancreas: is it worthwhile? J Gastrointest Surg 2002;6:147-157.

31 Mitchem JB, Hamilton N, Gao F, Hawkins WG, Linehan DC, Strasberg SM: Long-term results of resection of adenocarcinoma of the body and tail of the pancreas using radical antegrade modular pancreatosplenectomy procedure. J Am Coll Surg 2012;214:46-52.

32 Burdelski CM, Reeh M, Bogoevski D, Gebauer F, Tachezy M, Vashist YK, Cataldegirmen G, Yekebas E, Izbicki JR, Bockhorn M: Multivisceral resections in pancreatic cancer: identification of risk factors. World J Surg 2011; 35:2756-2763. 
33 Tseng JF, Raut CP, Lee JE, Pisters PW, Vauthey JN, Abdalla EK, Gomez HF, Sun CC, Crane CH, Wolff RA, Evans DB: Pancreaticoduodenectomy with vascular resection: margin status and survival duration. J Gastrointest Surg 2004;8:935-949.

34 Martin RC 2nd, Scoggins CR, Egnatashvili V, Staley CA, McMasters KM, Kooby DA: Arterial and venous resection for pancreatic adenocarcinoma: operative and long-term outcomes. Arch Surg 2009;144:154-159.

35 Gong Y, Zhang L, He T, Ding J, Zhang H, Chen G, Zhang D, Wu Z, Chen Q, Fan H, Wang Q, Bie P, Wang H: Pancreaticoduodenectomy combined with vascular resection and reconstruction for patients with locally advanced pancreatic cancer: a multicenter, retrospective analysis. PLoS One 2013;8:e70340.

36 Ramacciato G, Mercantini P, Petrucciani N, Giaccaglia V, Nigri G, Ravaioli M, Cescon M, Cucchetti A, Del Gaudio M: Does portal-superior mesenteric vein invasion still indicate irresectability for pancreatic carcinoma? Ann Surg Oncol 2009;16:817-825.

37 Tang D, Zhang JQ, Wang DR: Long term results of pancreatectomy with portal-superior mesenteric vein resection for pancreatic carcinoma: a systematic review. Hepatogastroenterology 2011;58:623-631.

38 Chua TC, Saxena A: Extended pancreaticoduodenectomy with vascular resection for pancreatic cancer: a systematic review. J Gastrointest Surg 2010;14:1442-1452.

39 Zhou Y, Zhang Z, Liu Y, Li B, Xu D: Pancreatectomy combined with superior mesenteric vein-portal vein resection for pancreatic cancer: a meta-analysis. World J Surg 2012;36:884-889.

40 Glebova NO, Hicks CW, Tosoian JJ, Piazza KM, Abularrage CJ, Schulick RD, Wolfgang CL, Black JH 3rd: Outcomes of arterial resection during pancreatectomy for tumor. J Vasc Surg 2016;63:722-729.e1.

41 Mollberg N, Rahbari NN, Koch M, Hartwig W, Hoeger Y, Büchler MW, Weitz J: Arterial resection during pancreatectomy for pancreatic cancer: a systematic review and meta-analysis. Ann Surg 2011;254:882-893.

42 Christians KK, Pilgrim CH, Tsai S, Ritch P, George B, Erickson B, Tolat P, Evans DB: Arterial resection at the time of pancreatectomy for cancer. Surgery 2014;155:919-926. 